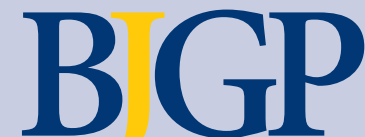

EDITOR

Roger Jones, DM, FRCP, FRCGP, FMedSci London

DEPUTY EDITOR

Alec Logan, FRCGP

Motherwell

JOURNAL MANAGER

Catharine Hull

SENIOR ASSISTANT EDITOR

Erika Niesner

ASSISTANT EDITOR

Moira Davies-Cinar

EDITORIAL ASSISTANT

Tania Marszalek

ADVERTISING EXECUTIVE

Brenda Laurent

EDITORIAL BOARD

Richard Baker, MD, FRCGP

Leicester

Stephen Barclay, MD, FRCGP, DRCOG

Cambridge

Jenny Blythe, MRCGP, DRCOG, DCH

London

Chris Butler, MD, MRCGP

Cardiff

Kath Checkland, PhD, MRCGP

Manchester

Graham Easton, MSc, MRCGP

London

Mark Gabbay, MD, FRCGP

Liverpool

Murray Lough, MD, FRCGP

Glasgow

Nigel Mathers, MD, FRCGP, DCH

Sheffield

Tim Peters, MSc, PhD, CStat, FFPH

Bristol

Bruno Rushforth, MRCGP, DFSRH, DRCOG

Leeds

Chris Salisbury, MD, FRCGP

Bristol

John Sandars, MSc, MD, FRCGP, MRCP

Leeds

Mark Shapley, FRCGP, DCH, DRCOG

Newcastle-under-Lyme

Niroshan Siriwardena, MMedSci, PhD, FRCGP Lincoln

2009 impact factor: $\mathbf{2 . 4 4 2}$

EDITORIAL OFFICE

1 Bow Churchyard, London, EC4M 9DQ

(Tel: 0203188 7400, Fax: 0203188 7401).

E-mail: journal@rcgp.org.uk

http://www.rcgp.org.uk/bjgp.aspx

PUBLISHED BY

The Royal College of General Practitioners,

1 Bow Churchyard, London, EC4M 9DQ.

Registered charity number 223106. The BJGP is

published by the RCGP, but has complete

editorial independence. Opinions expressed in the

BJGP should not be taken to represent the policy

of the RCGP unless this is specifically stated.

No endorsement of any advertisement is implied or intended by the RCGP.

PRINTED IN GREAT BRITAIN BY

HPM Limited, Prime House, Park 2000, Heighington

Lane Business Park

Newton Aycliffe, Co. Durham DL5 6AR.

Printed on $100 \%$ recycled paper

ISSN 0960-1643 (Print)

ISSN 1478-5242 (Online)

March Focus

\section{GENERALISM AT THE CENTRE OF CARE}

There is, it seems, a continuing need to make and re-make the argument that a strong, generalist primary care sector is an essential part of any effective healthcare system. Governments tend to equate investment in health with opening hospitals and buying high-tech equipment. This issue of the BJGP highlights and celebrates many facets of primary care and its engagement with the public health.

Starting at the sharp end, Haj-Hassan and colleagues' study from Oxford (page 171) itemises the key, early 'red flag' symptoms found in children with meningitis - leg pain, confusion, neck pain or stiffness, and photophobia are the cardinal symptoms, whereas pallor, headache, and cool peripheries are non-discriminatory. Khan and co-workers' study (page 197) is another reminder of the role of general practice in dealing with serious illness, in this case cancer: survivors of breast, colon, and prostate cancer consult their GPs up to three times more frequently than controls, with implication for both workload and training.

The interface between general practice and public health has always been an interesting one, and is likely to change again in the UK following the publication of Healthy Lives, Healthy People. Steve Gillam provides a trenchant critique of this important area of policy and practice (page 169), while Graham Watt, grappling with general practice at the deep end, sees the pay-offs from investing in health improvement as accumulating gradually over time, like compound interest (page 228). Garrett and colleagues, reporting from New Zealand (page 212), demonstrate the costeffectiveness of physical activity interventions, even over a 12-month period. Neilson and Walker's study from Glasgow (page 173) strongly suggests that screening for testicular descent in older boys should be re-instated.

Schieber and colleagues from France (page 178) sound a note of caution in the health promotion arena, however. Studying patients' and doctors' accounts of consultations involving cardiovascular risk management, they identified significant mismatches in understanding between them, particularly in relation to advice about nutrition and exercise. They recommend taking care to think about patients' social context, and Watt makes the same point about context in discussing the need for more flexible and imaginative approaches than 'health checks' when working in areas of deprivation and difficulty. Rather similar challenges are presented to GPs when faced with decisions about certification of longterm sickness and incapacity. The NICE guidance provides some helpful pointers but Gabbay's group points out the need for more research evidence to inform these decisions, and for better collection of data about work ability along with its greater use as an outcome measure in trials of interventions (page 206).

Two articles discuss the health of children and young people in the wake of the Kennedy report on the cultural barriers to providing good care for them, and the Royal College of General Practitioners' Child Health Strategy. Mathers and Harnden (page 165) recommend more training and a stronger clinical focus on child health, perhaps something to consider in relation to extending the training period for GPs in the UK - which differs from a number of other countries where the care of children is as much, or more, the province of paediatricians as of GPs. Jane Roberts was struck by the success of Kid's Company, a charity for children living in fragile and difficult circumstances, and this perhaps is another vision of how multidisciplinary primary care needs to be to respond to everything that is thrown at it (page 227).

The identity and attributes of the future GP - tomorrow's generalist - are examined from two very different perspectives. Lakhani's James Mackenzie lecture (page 218) gives us an optimistic and inspiring vision of the future GP, who has evolved out of the best of present-day practice, working in an organisation in which integration - clinical, academic, and informational - is the watchword and where professional autonomy has survived. Greenhalgh and Wong (page 166) use revalidation as the mirror, and see overregulation, a mechanistic medical model, and the rhetoric of managerialism as the threats to the 'good doctor' - someone in whom experience and knowledge, wisdom and understanding, and a conscientious professionalism are brought together in the care of patients and populations.

\section{Roger Jones \\ Editor}

DOI: 10.3399/bjgp11X561087

(c) British Journal of General Practice 2011; 61: 161-240. 